\title{
The Hunter Gracchus: A Franz Kafka Story of Death’s Dehumanization
}

\author{
Gabriella D’Angiolella, Pamela Tozzo, Luciana Caenazzo \\ University of Padova, Padova, Italy
}

\begin{abstract}
A key benefit of publishing illness narratives is giving voice to sick or dying people, in order to promote a deepened understanding of patients' experiences of illness. Reading this kind of stories can also help healthcare providers to reflect about facing the difficult concept of "a good death" (a good way to die). Following considerations arise from a close reading of Franz Kafka's incomplete short story entitled "The Hunter Gracchus" (1917) and, in particular, from the condition in which he puts the protagonist, the Hunter Gracchus. Kafka creates a completely surrealistic story concerning the artificial extension of persistently compromised vital functions of a person affected by an irreversible pathology. The protagonist, who seems to be aware of his poor condition, is really distressed by living the dying process spread over a long time and so diluted. Realistic connotations of this short story were not clear at Kafka's time, but, nowadays, because of advances in medicine, with the availability of medications or invasive interventions developed to prolong life, many patients can experience a condition similar to hunter Gracchus's one. We believe, therefore, that could be important reading and then reflecting on this story, especially assuming the hunter's point of view, for the purpose of developing a new approach to the current problem of the "dehumanization" of dying. To make the reflection process as free as possible, we thought that it would have been better to give the voice to the Poet, and for this reason, we tried to avoid adding words of "wisdom” to support one thesis or another. In our opinion, reflecting upon the specific experience of a person who is practically dead but still not allowed to die could encourage health-care providers to consider meaning and consequences of serious illnesses, exploring their feelings about life-sustaining treatments and death.
\end{abstract}

Keywords: dehumanization of dying, narrative medicine, illness narratives, reflection, Hunter Gracchus

\section{Introduction}

Medicine has grown significantly in its ability to diagnose and treat biological disease, but despite such impressive technical progress, doctors may lack the human capacity to recognize the complexity of their patients, to extend empathy toward those who suffer, and to join honestly and courageously with patients both in their struggles toward recovery and in facing chronic illnesses or death (Charon, 2006, p. 3).

Nowadays, in fact, medical practice is dominated by evidence-based medicine, based on the clinical trials

Acknowledgements: We wish to thank Professor Daniele Rodriguez for making us aware of this Kafka's inspiring novel.

Gabriella D’Angiolella, Dr., Department of Cardiac, Thoracic, Vascular Sciences and Public Health, University of Padova, Padova, Italy.

Pamela Tozzo, Dr., Department of Molecular Medicine, Laboratory of Forensic Genetics, University of Padova, Padova, Italy.

Luciana Caenazzo, Dr., professor, Department of Molecular Medicine, Laboratory of Forensic Genetics, University of Padova, Padova, Italy. 
science, numbers, probabilities, confidence intervals, and completely aloof to subjective elements, personal perceptions, opinions, or preferences.

Physicians make a special effort to integrate best evidence with clinical expertise, but often fail to reflect on their effective role as healthcare providers. The progressive weakening of physicians' empathy and humanitarian perspectives often leads them to the adoption of a detached and dogmatic approach to medical practice (Batistatou, Doulis, Tiniakos, Anogiannaki, \& Charalabopoulos, 2010, pp. 241-243).

In this contest, Medical Humanities, an interdisciplinary field of humanities (theory of literature and arts, philosophy, ethics, history, and religion), social sciences (anthropology, cultural studies, psychology, and sociology), and arts (literature, theatre, cinema, and visual arts) and their application to medical education and practice, can help healthcare professionals acquire a better understanding of the human condition.

Many humanities-history, medical anthropology, sociology, and literature-help to increase understanding of human experiences and human cultures, including how cultures understand and deal with death, health, and disease; and how cultural beliefs, biases, and needs are reflected in the structure of medical practice. Narrative medicine, which is one of the central components of Medical Humanities, could therefore help to develop empathy and compassion for patients.

A key benefit of publishing illness narratives, in fact, is giving voice to sick or dying people, promoting a deepened understanding of patients' experiences of illness.

Healthcare professionals may appreciate intrinsic therapeutic and palliative characteristics of illness narratives, because, as human beings, they have daily experiences that they often try to make meaningful; furthermore, as readers, they try to make sense of characters' experiences and reconstruct their meanings since this allows to engage in a type of personal reflection about complex feelings and responses to life events.

Moreover, reading this kind of stories can help healthcare providers to reflect about facing the difficult concept of what can be defines as "a good death" or a good way to die.

Over the last three decades, the humanities training for physicians has been considered as a fundamental instrument to reach healthcare professional's interior development, and so has been increasingly incorporated into medical school curricula (Mukunda et al., 2019). The teaching of literature in some medical school has been accepted as a primary mean to strengthen reflection, self-awareness, and adoption of patients' perspectives. The healthcare professional equipped with capacity to recognize the patient's complexity and to respond with reflective engagement can achieve more effective treatment than healthcare professional unequipped of these capacities.

Therefore, currently, narrative medicine is taught and applied in a lot of centres worldwide, but the two main schools of thought are London's King's College Center for Humanities for Health and the New York Columbia University Medical Center, Program in Narrative Medicine.

Brian Hurwitz and Tricia Greenhalgh of King's College in London were the first to describe the benefits of this discipline in healthcare practice, stating that

the narrative provides meaning, context, and perspective for the patient's predicament. It defines how, why, and in what way he or she is ill. The study of narrative offers a possibility of developing an understanding that cannot be arrived at by any other means. (Greenhalgh \& Hurwitz, 1999, pp. 367-369)

Rita Charon, at Columbia University in New York, first theoretically defined narrative medicine in referring to clinical practice as medicine practiced with the narrative competence to observe, interpret, and be 
moved by stories of illness (Charon, 2001, pp. 1897-1902).

Whenever possible, medical humanities and professionalism instructions should involve collaboration among faculty from different disciplines to reinforce the team approach required in clinical practice.

One pedagogical technique is to invite learners to read narrative text in which they have raised aspects of ethical issues.

The doctor-patient relationship has undergone a transition throughout the ages (Kaba \& Sooriakumaran, 2007, pp. 57-65). Today, we are witnesses of a remarkable reduction of the time available for conversation between healthcare professional and patient, with an important limitation of the continuity of clinical relationships; in this context, it arises the importance of telling and listening to the stories of illness, because, as practice speeds up, healthcare providers need all most powerful methods for achieving empathic and effective therapeutic relationships. Listening to stories of illness and recognizing that there are often no clear answers to patients' narrative doubts can improve the physician-patient therapeutic alliance, through conveying empathy for patient's experiences, in order to engage the patient in obtaining effective care (Charon, 2001, pp. 1897-1902).

An emotion does not usually constitute scientific evidence and, therefore, it is not demonstrative of some truth, but it can constitute a cue for the reader's personal reflection, because, in this case, the topic, the dehumanization of death, is one of those on which a lot has been argued in the current bioethical debate (Davis, 2001, pp. 239-246; Doyal, 1999, pp. 1432-1433; Kuhse \& Singer, 1991, pp. 205-206; Twycross, 2005, p. 639). Nowadays, the availability and effectiveness of life-prolonging treatments move into a domain where the boundary limit of the obligation to preserve life is less clearly defined.

When life prolongation is guaranteed by ongoing caregivers' interventions, caregivers are morally troubled as their treatments prolong the process of dying, especially if at the time of treatment beginning no one could have expected a such poor outcome with deteriorated residual life (Reynolds, Cooper, \& McKneally, 2007, pp. 919-936).

\section{The Hunter Gracchus and the Death}

The following considerations arise from our desire to share with other people an emotion which is born from the reading of Franz Kafka’s incomplete short story "The Hunter Gracchus” (1917) and, in particular, from the condition in which the author puts the protagonist, the Hunter Gracchus.

In our opinion, it is suitable reading this story without the addition of words of "wisdom" to comfort one thesis or another, giving directly the voice to the poet, particularly when its sensibility picks the point of view of the person who suffers.

Furthermore, this point of view appears deeply reliable and realistic, since the sensibility on which it is based is related to painful experiences, like the ones reserved to Kafka himself by life.

From our perspective, reading “The Hunter Gracchus” novel constitutes a great opportunity to propose to others an approach to the problem of the dehumanization of dying, not burdened by the rigor of the normative references or by the heavy depth of "learned men". In fact, the Hunter Gracchus, who speaks on behalf of the author Kafka, is perpetually destined to live the anguish of dying for other people's will and the emotions stirred up from his words represent the reaction to self-determination's violation of someone whose will has been acted dishonestly.

The hunter's point of view acquires a particular value in relation to the feelings of the health care 
professional who, involved as reader, draws up them in egoistic way, getting ready to take professional decisions to protect himself, and therefore condemning the patient to an experience of undesired anguish. For the patient, the anguish is twofold: not only the one related to the dehumanized death, but also the one which derives from the consciousness that his requests have not been granted by the people in which he had placed his confidence.

The circumstance described by Kafka is completely surrealistic: That is why it is better avoiding every rational control on the vicissitude and giving free course, with simplicity, to the descriptions, to the narration of the Hunter Gracchus, whose knowledge seems to be changeable during the story, and to the childish questions of the interlocutor (the burgomaster), who is the mayor of the city.

It seems that Kafka himself does not know what he is writing, unless he wanted to place the text in a kabbalistic symbolism that could also be coherent to the purposes of the author.

Kafka creates a story on a theme whose realistic connotations were not clear at his time. Nowadays, indeed, the artificial extension of persistently compromised vital functions is an actual concern of people, affected by irreversible pathology, who are consciously distressed by the idea of living the dying process diluted in time.

\section{The Hunter Gracchus Story}

In the small port of a town, on an Italian lake river, a boat reaches silent. Then, the narration slips out of Kafka's hands, because this story is not only the narration of the Hunter Gracchus' condition (dead-not dead man transported in a coffin on a boat), but it gives voice to his feelings in questioning on his condition. The questions are not of philosophical since they regard, precisely, the human responsibilities, in particular the responsibilities of people who force the Hunter Gracchus to ramble, against its will, in a condition of which he cannot understand the reason, while it is very clear to him the meaning of living and dying.

Basic aspects of his questionable situation are described in the following passage:

The hunter nodded and pushed the tip of his tongue between his lips. "Yes, the doves fly here before me. But do you believe, Burgomaster, that I am to remain in Riva?”

“That I cannot yet say,” answered the burgomaster. “Are you dead?”

"Yes," said the hunter, "as you see. Many years ago-it must have been a great many years ago—I fell from a rock in the Black Forest-that’s in Germany—as I was tracking a chamois. Since then I’ve been dead.”

“But you're also alive,” said the burgomaster.

“To a certain extent," said the hunter, “to a certain extent I am also alive. My death ship lost its way-a wrong turn of the helm, a moment when the helmsman was not paying attention, a distraction from my wonderful homeland-I don’t know what it was. I only know that I remain on the earth and that since that time my ship has journeyed over earthly waters. So I-who only wanted to live in my own mountains - travel on after my death through all the countries of the earth.”

“And have you no share in the world beyond?” asked the burgomaster wrinkling his brow.

The hunter answered, "I am always on the immense staircase leading up to it. I roam around on this infinitely wide flight of steps, sometimes up, sometimes down, sometimes to the right, sometimes to the left, always in motion. From being a hunter I’ve become a butterfly. Don’t laugh.”

"I’m not laughing," answered the burgomaster. 
“That's very considerate of you,” said the hunter. "I am always moving. But when I go through the greatest upward motion and the door is shining right above me, I wake up on my old ship, still drearily stranded in some earthly stretch of water. The basic mistake of my earlier death grins at me in my cabin. Julia, the wife of the helmsman, knocks and brings to me on the bier the morning drink of the country whose coast we are sailing by at the time. I lie on a wooden plank bed, wearing—I'm no delight to look at—a filthy shroud, my hair and beard, black and gray, are inextricably intertangled, my legs covered by a large silk women's scarf, with a floral pattern and long fringes. At my head stands a church candle which illuminates me. On the wall opposite me is a small picture, evidently of a bushman aiming his spear at me and concealing himself as much as possible behind a splendidly painted shield. On board ship one comes across many stupid pictures, but this is one of the stupidest. Beyond that my wooden cage is completely empty. Through a hole in the side wall the warm air of the southern nights comes in, and I hear the water lapping against the old boat.

I have been lying here since the time when I-the still living hunter Gracchus—was pursuing a chamois to its home in the Black Forest and fell. Everything took place as it should. I followed, fell down, bled to death in a ravine, was dead, and this boat was supposed to carry me to the other side. I still remember how happily I stretched myself out here on the planking for the first time. The mountains have never heart me singing the way these four still shadowy walls did then.

I had been happy to be alive and was happy to be dead. Before I came on board, I gladly threw away my rag-tag collection of guns and bags, even the hunting rifle which I had always carried so proudly, and slipped into the shroud like a young girl into her wedding dress. There I lay down and waited. Then the accident happened.”

"A nasty fate," said the burgomaster, raising his hand in a gesture of depreciation, "and you are not to blame for it in any way?”

"No," said the hunter. "I was a hunter. Is there any blame in that? I was raised to be a hunter in the Black Forest, where at that time there were still wolves. I lay in wait, shot, hit the target, removed the skin-is there any blame in that? My work was blessed. 'The great hunter of the Black Forest'-that's what they called me. Is that something bad?”

"It not up to me to decide that," said the burgomaster, "but it seems to me as well that there's no blame there. But then who is to blame?”

“The boatman," said the hunter.

\section{Discussion}

As previous described, medical practice should also require "narrative competence". Literary studies can teach healthcare professionals how to perform narrative aspect of their practice, giving them the skills to comprehend with new effectiveness various aspects of health and illness, and their consequences and meaning for individual patients and other healthcare providers.

The picture outlined by the story describes a narrative dimensions of illness: The Hunter Gracchus is a man who has lived, who has encountered the death, and who expected to be received by death in a natural dimension; his job, which consisted in giving death to the hunted animals, is, in his opinion, a blessed job; the death, therefore, belonging to the natural course of living and dying, is blessed for men.

In Kafka's incomplete story, instead, every morning, the death is inexorably kept away from the Hunter Gracchus, because of an inscrutable and mysterious ritual performed by the captain's wife, who daily brings to the hunter the morning drink of the country whose coast is sailed by the boat that was simply supposed to carry the hunter to the other side. The burgomaster is the reference authority: That is why the Hunter Gracchus addresses, with great dignity, just to him. Nevertheless, this character has an annoying naivety that seems to derive more from superficiality than from innocence and he wraps Hunter Gracchus' loneliness in hypocrisy. The burgomaster in this dialogue points out to be shocked by Hunter Gracchus' situation, but he merely wrinkles his brow listening to the hunter's struggles and seems not really capable of sharing his feelings. The 
guilty remains on the background: It is the boatman, who is responsible for having created a situation (that is also maintained by captain's wife) that forces the Hunter Gracchus to suffer, wondering about the reasons he is not allowed to reach the other side. The hunter's dignity does not allow him to move explicit accusations to the boatman. The Hunter Gracchus describes his persistent anguish related to the process of extending dying process to infinity: "On the wall opposite me is a small picture, evidently of a bushman aiming his spear at me and concealing himself as much as possible behind a splendidly painted shield”.

The hunter's attitude towards the boatman who takes the helm and makes decisions on his behalf reveals his real feelings of rejection: "The thought of wanting to help me is a sickness and has to be cured with bed rest”. There is little to argue about that statement: There is a clear difference between aid-relationship and "presumption of aid", which is a concept not really far away from ancient medical paternalism, especially when this kind of "aid" is not requested by the Hunter Gracchus, who does not understand its necessity.

Evidently this Kafka's short story must be read in its entirety: We have proposed a starting point of reflection that gives only a partial and subjective point of view.

Even though the story is incomplete, more fragments are known (Kafka, 1995), with some of them partially overlapped, creating parallel and lightly different descriptions in some passages.

\section{Conclusion}

The emotions evoked by this literary fiction may have wide ranging influences on healthcare providers because, once the reader has finished reading, emotions he felt do not easily dissipate, but may have an impact that lasts in time, perhaps re-emerging whenever a similar situation occurs.

Acting with "narrative competence”, recognizing patients' personal needs through medicine, and bridging the gap that sometimes keeps physicians far from who suffers offers the opportunity to realize respectful and empathic medical care.

Healthcare providers can cultivate affirmation of human strength, and the acceptance of human weakness only through an authentic engagement with their patients.

We can consider this story as an example of a human vicissitude in its various facets. Unfortunately, it is not possible to ask, neither Franz Kafka nor the Hunter Gracchus, the key for the solution of this vicissitude. It is up to the boatman finding this key.

\section{References}

Batistatou, A., Doulis, E. A., Tiniakos, D., Anogiannaki, A., \& Charalabopoulos, K. (2010). The introduction of medical humanities in the undergraduate curriculum of Greek medical schools: Challenge and necessity. Hippokratia, 14, $241-243$.

Charon, R. (2001). The patient-physician relationship. Narrative medicine: a model for empathy, reflection, profession, and trust. Journal of the American Medical Association (JAMA), 286, 1897-1902.

Charon, R. (2006). Narrative medicine: Honoring the stories of illness. Oxford; New York: Oxford University Press.

Davis, D. S. (2001). Is life of infinite value? Kennedy Institute of Ethics Journal, 11, 239-246.

Doyal, L. (1999). The moral character of clinicians or the best interests of patients? British Medical Journal (BMJ), 318, 1432-1433.

Kaba, R., \& Sooriakumaran, P. (2007). The evolution of the doctor-patient relationship. International Journal of Surgery, 5, 57-65.

Kafka, F. (1995). The complete stories. New York, NY: Schocken Books.

Kuhse, H., \& Singer, P. (1991). Prolonging dying is the same as prolonging living-one more response to long. Journal of Medical Ethics, 17, 205-206.

Greenhalgh, T., \& Hurwitz, B. (1999). Why study narrative? Western Journal of Medicine, 170, 367-369. 
Mukunda, N., Moghbeli, N., Rizzo, A., Niepold, S., Bassett, B., \& DeLisser, H. M. (2019). Visual art instruction in medical education: a narrative review. Medical Education Online, 24, 1-7.

Reynolds, S., Cooper, A. B., \& McKneally, M. (2007). Withdrawing life-sustaining treatment: Ethical considerations. Surgical Clinics of North America, 87, 919-936.

Twycross, R., Morris, C. R., Freshwater, G. T., \& McKay, A. C. (1999). When doctors might kill their patients. British Medical Journal, 319, 639-640. 